\title{
Tympanic Paraganglioma
}

National Cancer Institute

\section{Source}

National Cancer Institute. Tympanic Paraganglioma. NCI Thesaurus. Code C8428.

A benign or malignant middle ear parag ang lioma arising from parag ang lia around the

tympanum. Signs and symptoms include a mass behind the tympanum, tinnitus, and conductive hearing loss. 